\title{
VARIANT DESIGNING IN THE PRELIMINARY SMALL SHIP DESIGN PROCESS
}

\author{
Artur Karczewski \\ Janusz Kozak \\ Gdańsk University of Technology, Poland
}

\begin{abstract}
Ship designing is a complex process, as the ship itself is a complex, technical multi-level object which operates in the air/water boundary environment and is exposed to the action of many different external and internal factors resulting from the adopted technical solutions, type of operation, and environmental conditions. A traditional ship design process consists of a series of subsequent multistage iterations, which gradually increase the design identification level. The paper presents problems related to the design of a small untypical vessel with the aid of variant methodology making use of optimisation algorithms. The computer-aided design methodology has been developed which does not need permanent reference to already built real ships and empirical-statistical relations. Possibilities were indicated for integrating together early design stages, and parallel designing of hull shape and parameters.
\end{abstract}

Keywords: ship design,design methodology, optimisation algorithms

\section{INTRODUCTION}

The ship design theory deals with issues relating to basic technical [1] and economic properties of the designed ship, which are frequently determined using optimisation techniques [2]. This mainly refers to parameters which substantially affect the cost of shipbuilding (and purchase), and the cost of ship operation [2]. Ship designing is a complex process, as the ship itself is a complex, technical multi-level object which operates in the air/water boundary environment and is exposed to the action of many different external and internal factors resulting from the adopted technical solutions, type of operation, and environmental conditions. A traditional ship design process consists of a series of subsequent multistage iterations, which gradually increase the design identification level. The initial design process stage, performed with the aid of the ship design theory, bears the name of preliminary design, or pre-design [3][4][2]. In the next stages, the approximation obtained in the previous stage is subject to verification and, if necessary, correction. Particularisation levels reached by successive approximations are illustrated by the Evans design spiral [2][4][5].

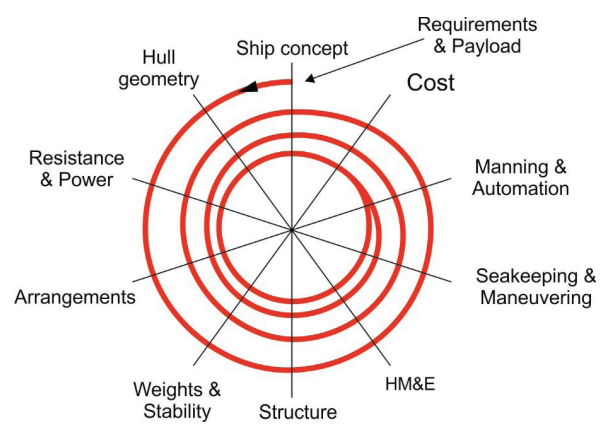

Fig.1-1. The Evans design spiral

Decisions made at each design process stage determine further design work. At the pre-design stage, the main parameters, which directly affect the design goals to be reached, are determined. Mistakes made at this stage are rather unlikely to be corrected in further, more detailed stages [5]. The requirement that the design theory methods should reveal highest correctness, accuracy and reliability, justifies the need for the research oriented on their improvement, by minimising the number and importance of wrong decisions, as well as by reducing labour intensity and costs [4]. 
Ship designing takes into account many criteria, which are frequently in opposition to each other. For a single design stage the design task can be considered a single-criterion task, but in general it is a multi-criterion problem. Multicriterion models require, as a rule, simplified models and calculation methods. They also need process decomposition and minimisation of the number of the applied criteria. The used ship pre-design method depends on the level of novelty of a given task. Here, distinction can be made between the following methods determined by the initial situation:

- comparative method [6],which consists in ship designing using a benchmark ship of the same type and similar size, and approximating parameters of the benchmark ship onto the designed ship [4],

- analytical method [6], which consist in designing the ship of a well-known type, but different size than the already designed ships. Here, use is made of statistical and/or empirical relations which reflect past knowledge gained when designing the population of already built ships [4]

- variant method [6], used in designing a ship of entirely new type. This method consists in analysing a series of variants, which are often subject to optimisation with respect to a given criterion.

The two first methods are applicable when the design task is typical and we have knowledge about properties of the already built real ships [7]. When a new, untypical ship is to be designed, multi-variant parallel designing [5][8] is frequently used, with further optimisation of the designed variants [6]. This method bases on analytical descriptions of selected properties of the designed ship as functions of its main operating characteristics, and makes use of relevant automatic calculation systems and modelling software.

The variant method makes use of given tools to determine the hull shape and properties, consolidating all tools into one optimisation algorithm. A possibility to use numerical methods and computer visualisation along with specialised engineering software facilitates the use of the shape predesign method [9]. In general, algorithmization and precise structure of the design process open up new possibilities for developing hi-tech ship design methodology [4].

\section{MULTI-CRITERION OPTIMISATION ISSUES}

Engineering practice is frequently in opposition to the optimisation theory. During the design process, many decisions are made a priori, based on past experience, knowledge, and intuition of the designer. A real engineering task has more than one target function [10], as the designed ship is expected to meet many different requirements. The task becomes a multi-criterion task, and the general solution is obtained as a set of permissible poly-optimal solutions which meet the assumed criteria as close as possible and, simultaneously, fully satisfy all constraints [11].

Optimisation methods provide opportunities for creating a set of design variables for which the target function reaches the extremum (maximum or minimum). A classical approach to ship designing via successive iterations transforms the multi-criterion problem into a single-criterion task to be solved in one design step. When a large number of criteria are applied to reach the optimal solution, conflicts may have place between them, which means that the solution does not meet individually each criterion to a satisfying degree, and is only a compromise between them. In this situation, the multi-criterion optimisation problem is reduced to finding this compromise. In many cases it can be done by formulating an alternative criterion, based on heuristic knowledge on the optimised process, and using this criterion to find a compromise solution.

The single-criterion problem has well-defined structure, i.e. is solved using a model for which both the target function and the constraints have been already defined.

The multi-criterion problem may or may not have welldefined structure. In the case of multi-criterion programming models, the multidimensional problem has well-defined structure, while for specific problems, such as selection, classification, or ranking for instance, such structure does not exist. When the well-defined structure exists, the task has the form of multi-criterion type optimisation, otherwise it is a decision-making support problem. Frequently, a real design task needs combining those two approaches.

One of possible ways to obtain a solution to the multicriterion design problem is searching for a set of Paretooptimal solutions. In a simple interpretation, the solution is Pareto-optimal when a better solution cannot be found with respect to at least one criterion without its worsening with respect to other criteria. This principle is graphically shown in Fig. 2-1.

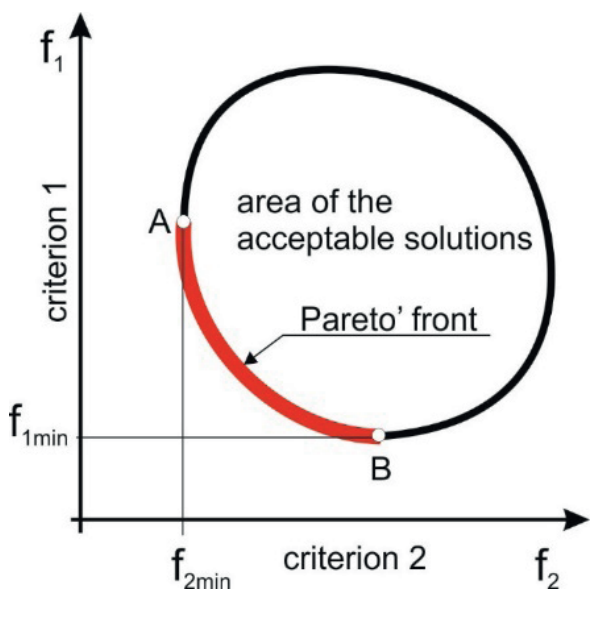

Fig.2-1. Definition of optimum in Pareto sense

The solutions situated along the red curve belong to the set of Pareto-optimal solutions. For each solution, any attempt to improve one criterion results in worsening the other criterion [12].These solutions compose a set of compromise variants, the so-called Pareto front, which makes the basis for making final design decisions. Selecting one variant from this set is burdened with subjectivity of assessment [5], and its acceptance depends on the tolerance assumed at a given design stage. 


\section{DESIGN PROCESS}

\section{DESIGN TASK}

The here presented design task consisted in designing an electric propulsion single deck ferry, equipped with two azimuth thrusters mounted under the hull, one in bow and one in stern part. The ferry was intended to operate autonomously on internal waters of the City of Gdansk (the river Motlawa) throughout the whole year, also in slightly crushed ice conditions [14].The ship should meet growing expectations of passengers and crews, along with UE regulations concerning environment protection [13][15].

\section{DESIGN ASSUMPTIONS}

The set of design assumptions (Table 3-1) taking into account substantial requirements resulting from ship owner's expectations, sailing conditions, classification society regulations [16] and international directives was the basis for determining the design parameters and shape of the hull, as well as the inner division and silhouette of the ship.

Tab. 3-1. Design assumptions

\begin{tabular}{|l|c|c|c|}
\hline Parameter & Symbol & Unit & Parameter value \\
\hline Functional type of ship & - & - & Inland ferry \\
\hline Architectural type of ship & - & - & $\begin{array}{c}\text { Symmetrical with } \\
\text { respect to midship }\end{array}$ \\
\hline Hull length & LH & M & 12,0 \\
\hline Hull breadth & B & M & 5,0 \\
\hline Number of persons & CL & Person & 36 \\
\hline Hull material & - & - & Steel \\
\hline Propulsion type & - & - & Azimuthal \\
\hline Number of propellers & - & - & 2 \\
\hline
\end{tabular}

According to the approach shown in Fig. 11, a number of aspects are to be taken into account when designing the ship hull. The ship should have the required displacement, at the same time fulfilling requirements concerning its lateral and longitudinal stability, and unsinkability. Moreover, for propulsion efficiency purposes, the shape of its underwater part should be refined enough to generate as low resistance as possible.

Applying the design procedure having the parallel and variant structure, in combination with sufficiently advanced automatic shape design methods, enabled to leave aside traditional designing of theoretical hull contours based on benchmark ships and designers' experience. The use of CAD software, which made it possible to create $3 \mathrm{D}$ visualisations, along with project parameterisation (what was equally important) provided good opportunities for unrestricted creation of links between different geometrical objects, and their transformations and functions. All this has made it possible to combine the parametric project phase and the ship hull design phase into one procedure, thus minimising the number of the performed iterations.

In the initial phase, the mass data were assessed using parametric formulas available in the literature [17]. In the later phase, they were corrected using a manual hull structure unit mass assessment method based on standard requirements [16]. Preliminary ship hull resistance assessments were made based on methods having simple algorithmic structure, which allowed them to be implemented in the spreadsheet, and a method available in the computer programming package. Stability and unsinkability were checked in computer simulations, by comparing the calculated values with standard criteria given in [16].

\section{ENVIRONMENTALCONDITIONS - TARGET FUNCTION}

In the case of a ferry operating in the urban space, the ecological aspect of sustainable ship designing requires focusing on two basic issues:

- applying a renewable energy based ship propulsion system, - minimising the required propulsion power by minimising hull resistance through optimisation of the obtained solutions.

\section{STRUCTURE OF THE DESIGN PROCESS}

An algorithm was worked out which combined together manual and automatic design approaches. The majority of initial data were assumed based on parametric methods available in the literature [17][18].

In the first phase, the hull shape was considered a variable, while the assumed constant parameters referred to design assumptions, sailing conditions in the selected water region, and the assessed value of the required displacement. The limiting constraints were the stability criteria and the area of the wetted surface of the hull. The target function to be minimised was the total hull resistance.

In the second phase, the type of hull shape was assumed constant, while the changing parameters concerned details of shape topology, for given geometrical limits, and criteria resulting from the adopted standards and buoyancy conditions. The target function remained unchanged.

\section{HULL SHAPE}

In the initial phase of the design process, eight different hull geometries were generated. All geometries were symmetrical with respect to longitudinal and lateral axes, and did not have protruding parts. They were based on traditional hull shape types, such as: flat-bottomed, spheroid, with a keel, and with cruiser stern [14]. The following criteria were taken into account:

- the maximum heel angle from wind and concentration of passengers on one ship's side (limit $=$ no more than $12^{\circ}$ ),

- the wetted surface area corresponding to the minimum friction resistance (criterion $=$ minimum), 
- the preliminary total hull resistance, calculated using the parametric method developed by the Leningrad Design Office (LBP) [17][18] and the model data based HoltropMennen (H-M) method included in the design programme module.

The results obtained for the examined hull geometries are shown inTable3-2.

The results obtained in this stage allowed selecting a shape situated between the cuboid and the spheroid for further optimisation. It was the hull No. 7, which revealed optimal properties for the assumed criteria. In this design process phase, use was made of a genetic algorithm included in the Grasshopper for Rhinoceros software [14].

Table3-2. Results of initial design phase
The final value of the required effective propulsion power was assessed as equal to $15 \mathrm{~kW}$.

\section{MASS CHARACTERISTICS, BUOYANCY EQUATION}

In the initial design project phase, the mass characteristics were calculated using analytical relations given in [17]. The results of these calculations are collated in Table 3-3, in which $\mathrm{ZG}$ is the vertical centre of mass coordinate above the assumed design load waterline, and $\mathrm{D}$ is the design displacement. Both the mass of the ship and the centre of mass position were assumed the same for all variants.

\begin{tabular}{|c|c|c|c|c|c|c|c|c|}
\hline No of hull & 1 & 2 & 3 & 4 & 5 & 6 & 7 & 8 \\
\hline Description & 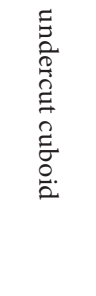 & 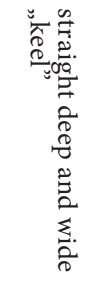 & 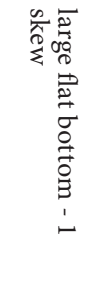 & 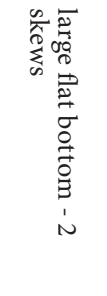 & 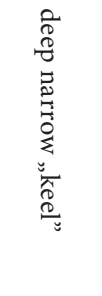 & 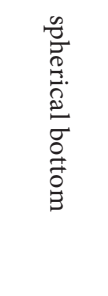 & 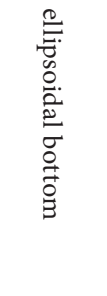 & 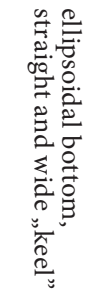 \\
\hline & $\square$ & 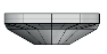 & $\approx$ & 10 & 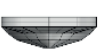 & + & + & $=$ \\
\hline Wetted surface $[\mathrm{m} 2]$ & 58,10 & 44,94 & 49,74 & 49,48 & 46,86 & 57,11 & 48,08 & 43,57 \\
\hline Heel angle $\left[^{\circ}\right]$ & 6,5 & 20,0 & 11,5 & 10,5 & 20,0 & 7,0 & 10,0 & 20,0 \\
\hline Trim angle $\left[^{\circ}\right]$ & 2,99 & 4,50 & 3,58 & 3,57 & 3,91 & 3,00 & 3,33 & 5,32 \\
\hline $\mathrm{H}-\mathrm{M}$ resistance $[\mathrm{N}]$ & - & 1845 & 1357 & 1352 & 1370 & 1238 & 1237 & 1397 \\
\hline LBP resistance $[\mathrm{N}]$ & 1476 & 1432 & 1305 & 1302 & 1287 & 1389 & 996 & 1326 \\
\hline
\end{tabular}

The applied optimisation criterion was the propulsion power which was minimised for given shape boundary conditions referring to: bow end height above water, positions of propeller axes, permissible draught, and position of collision bulkhead with respect to waterline, as well as to standard restrictions concerning permissible heel angle and minimum freeboard at heel.

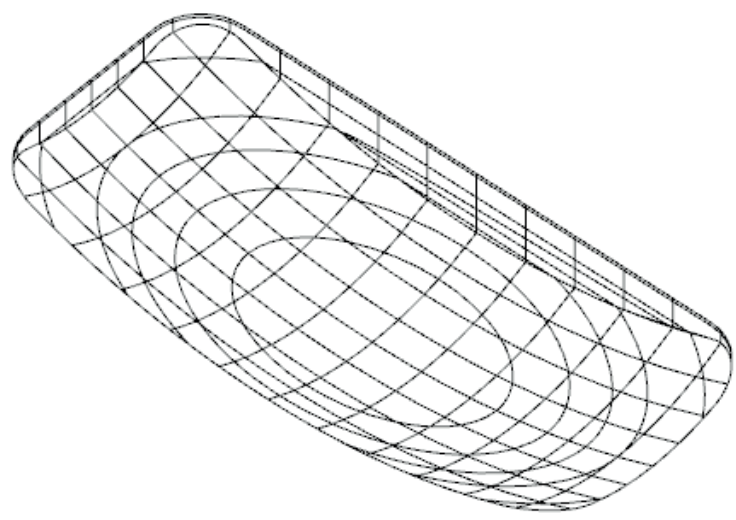

Fig.3-2. Hull shape
Table3-3. Mass characteristics

\begin{tabular}{|c|c|c|c|c|c|}
\hline \multicolumn{3}{|c|}{ Mass of empty ship } & \multicolumn{3}{|l|}{ Deadweight } \\
\hline Characteristic & Mass [t] & $\mathrm{ZG}[\mathrm{m}]$ & Characteristic & Mass [t] & $\mathrm{ZG}[\mathrm{m}]$ \\
\hline mass of hull & 7,69 & 0,53 & $\begin{array}{l}\text { mass of } \\
\text { passengers }\end{array}$ & 3,75 & 2,00 \\
\hline $\begin{array}{l}\text { mass of } \\
\text { superstructure }\end{array}$ & 1,44 & 2,40 & mass of crew & 0,23 & 2,00 \\
\hline $\begin{array}{l}\text { mass of engine } \\
\text { room }\end{array}$ & 1,50 & 0,35 & reserves & 0,50 & 2,00 \\
\hline $\begin{array}{l}\text { mass of } \\
\text { systems }\end{array}$ & 0,98 & 0,35 & Total & 4,48 & \\
\hline $\begin{array}{l}\text { mass of } \\
\text { equipment }\end{array}$ & 2,66 & 2,4 & & & \\
\hline $\begin{array}{l}\text { mass of hull } \\
\text { equipment }\end{array}$ & 0,53 & 0,35 & & & \\
\hline Total & 14,80 & & & & \\
\hline Reserves & 0,74 & & & & \\
\hline $\begin{array}{l}\text { Design } \\
\text { displacement }\end{array}$ & \multicolumn{2}{|c|}{$\mathrm{D}=20,02[\mathrm{t}]$} & \multicolumn{3}{|c|}{$\mathrm{ZG}=1,20[\mathrm{~m}]$} \\
\hline
\end{tabular}

In the final phase of optimal hull designing, the masses of individual structural groups were assessed based on the adopted distribution of structural hull elements and the corresponding minimal thickness of steel plating required by the Regulations [16] for a given water region. An empirical 
$22 \%$ correction was introduced to the mass of stiffeners. The value of this correction was assumed after analysing possible ship stiffener systems with certain structural nodes. The adopted hull structure system consisted of 6 transverse bulkheads, 2 longitudinal bulkheads, transverse frames, the crosslink system with ice-strengthening elements in the bow part, and the longitudinal stiffener system in the midship part, see Fig.3-3.

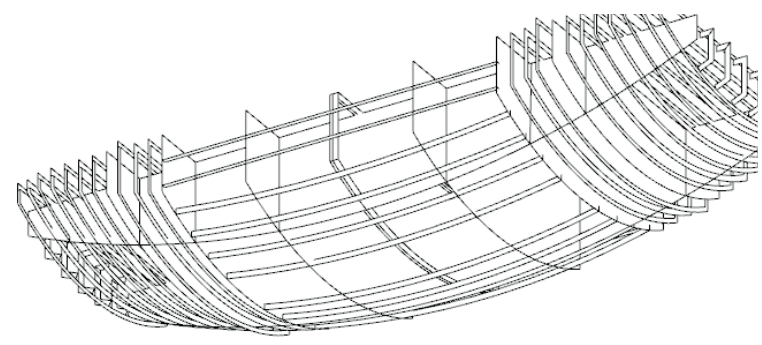

Fig.3-3. Model of hull structure

The masses of other weight groups were assessed either based on statistical values, or from already obtained real data, concerning, for instance the number and type of batteries, or the assumed propulsion type.

The final mass data assessed after completing this design phase were: $\mathrm{D}=23,1[\mathrm{t}], \mathrm{ZG}=1,02[\mathrm{~m}]$ (from load waterline).

\section{CHECKING CALCULATIONS - STABILITY AND UNSINKABILITY}

Each design project stage included check whether the stability requirements are fulfilled. Due to high freeboard assumed to meet operational restrictions, as well as small ship dimensions, $\mathrm{L} / \mathrm{B}=2,4$ [-], small number of passengers, absence of liquid reserves and limited sailing area, the stability criterion was fulfilled for the majority of the examined solutions. In the first project phase, in which the hull shapes were generated, the dimensioning constraint was the heel angle from wind and concentration of passengers and crew on one ship's side. The lateral ship area above the waterline was assumed based on the initial ship silhouette concept. The fulfilment of the adopted criteria was checked by relevant calculations performed on the generated hull shapes. The final hull shape was tested with respect to stability and unsinkability - Fig.3-4.

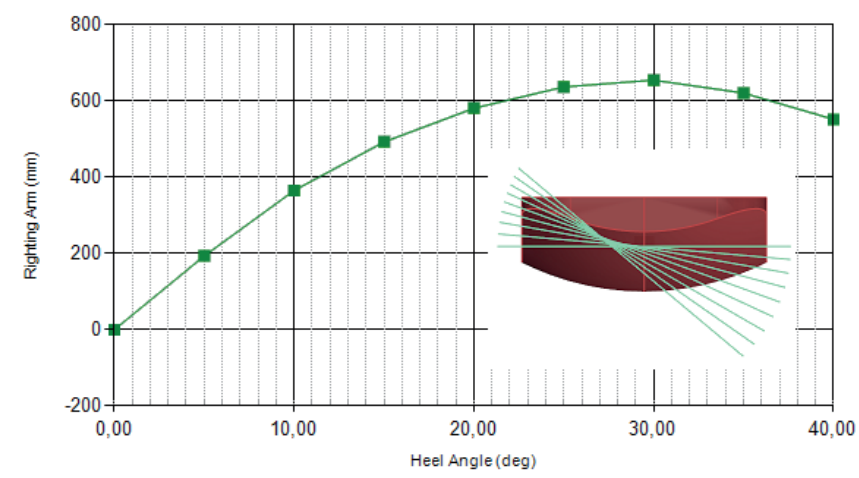

Fig.3-4. Stability test visualisation
Classification regulations [12] permit improving emergency unsinkability of the ship by dividing the internal space of the hull into compartments using waterproof transverse and longitudinal bulkheads, and by changing permeability of individual compartments via filling them, fully or partially, with non-absorbent displacement material. This method was used for external ship side spaces, as a result of which the ship became a displacement „cork”, regardless of the scale of destruction of an arbitrary compartment - Fig.3-5.

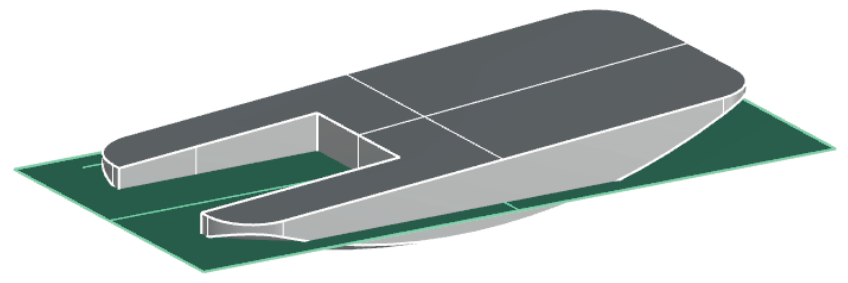

Fig.3-5. Emergency unsinkability test visualisation

\section{CONCLUSIONS}

For the purpose of ship hull body designing, two computer codes which generated its shape using, alternatively, the evolutionary algorithm and the iterative algorithm were developed [14]. The use of the genetic algorithm turned out helpful in determining basic hull parameters, without any restrictions concerning the number of input variables. However, in further calculations this algorithm turned out very time consuming, especially when some design assumptions were to be changed. On the other hand, despite its limited robustness the iterative algorithm turned out a good tool in designing the final hull version - Fig.4-1.

The adopted design procedure has revealed that the shape variant methods have potential to solve real tasks concerning preliminary designing of small ships. Combining optimisation algorithms with decision-making based design has made it possible to generate the ship hull shape which met the assumed target function.

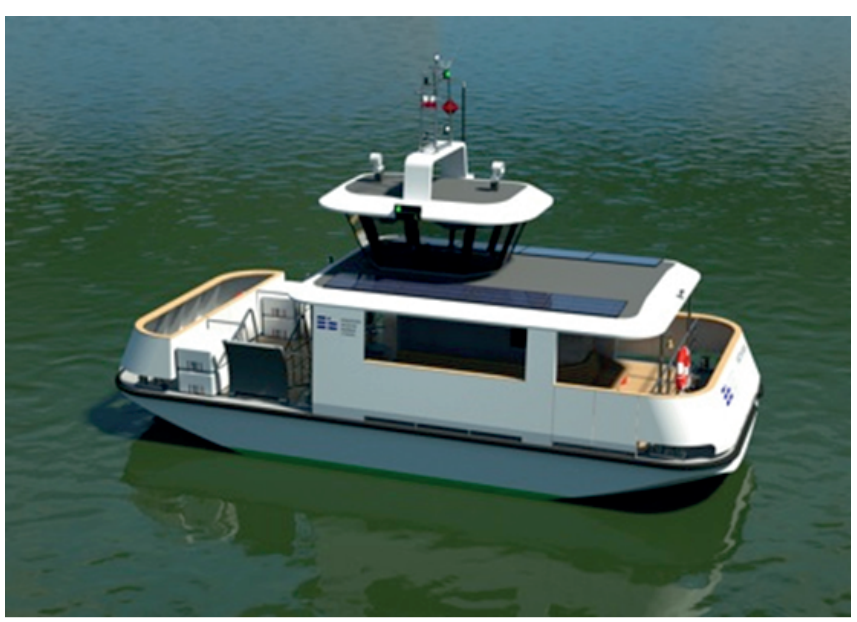

Fig.4-1. Visualisation of the designed ferry 
Another goal of the research was to gain more knowledge on designing a small untypical vessel with the aid of variant methodology making use of optimisation algorithms. The computer-aided design methodology has been developed which does not need permanent reference to already built real ships and empirical-statistical relations. Possibilities were indicated for integrating together early design stages, and parallel designing of hull shape and parameters.

\section{ACKNOWLEGDEMENT}

The research was performed and the ship design was made within the framework of the research project entitled: „Project of an ecological ferry for Gdansk city waters”, financed between June, 2015, and August, 2016, from the resources of the Regional Fund for Environmental Protection and Water Management in Gdansk. (http://www.wfosigwgda.pl).

\section{BIBLIOGRAPHY}

1. L. Nogid, Ship Design Theory (in Polish), Gdynia: Wydawnictwo Morskie, 1962.

2. A. Papanikolaou, Ship Design, Methodologies of Preliminary Design, London: Springer, 2014.

3. J. Wiśniewski, Ship design methodology issues (in Polish), Gdansk: Politechnika Gdańska, 1988.

4. J. Michalski, Principles of ship design theory (in Polish), Gdansk: Wydawnictwo Politechniki Gdanskiej, 2013.

5. Z. Sekulski, Selected issues of multi-criterion optimisation in preliminary hull design for sea-going vessels (in Polish), Szczecin: Wydawnictwo Uczelniane Zachodniopomorskiego Uniwersytetu Technologicznego w Szczecinie, 2012.

6. J. W. Piskorz-Nałęcki, Design of sea-going vessels (in Polish), Szczecin: Wydawnictwo Uczelniane Politechniki Szczecińskiej, 1981.

7. J. P. Michalski, Methods to calculate hull resistance and generalised masses which are applicable in preliminary design of small-waterline double-hull vessels (in Polish), Gdansk: Wydawnictwo Politechniki Gdańskiej, 2002.

8. W. Chądzyński, Elements of modern design methodology for selected objects (in Polish), Szczecin: Wydawnictwa Naukowe Politechniki Szczecińskiej, 2001.

9. J. Wiśniewski, Shape design in ship design methodology (in Polish), Gdansk: Politechnika Gdańska, 1979.
10. J. W. Z. Osiński, Theory of machine structures (in Polish), Warsaw: PWN, 1982.

11. W. Tarnowski, Principles of technical design (in Polish), Warsaw: Wydawnictwa Naukowo-Techniczne, 1997.

12. D. J. W. Panos Y. Papalambros, Principles of Optimal Design: Modelling and Computation, Cambridge University Press, 2000.

13. W. Kruszewski, "Modern pro-ecological technological solutions and technical devices in building and operation of inland and coastal ships. In Proceedings from INCOWATRANS Project.," Wydział Oceanoechniki i Okretownictwa, Gdansk, 2006.

14. A. Karczewski and Ł. Piątek, "Reducing the Environmental Impact of the Public Water Transportation Systems by Parametric Design and Optimization of Vessels' Hulls. Study of the Gdansk's Electric Passenger Ferry (20152016)," in Architecture for the Society of Knowledge, Warszawa, 2016.

15. E. Parliament, Directive 2002/88/EC of the European Parliament and of the Council of 9 December, 2002.

16. Rules for the Classification and Construction of Inland Ships (in Polish) Gdansk: Polish Register of Shipping, 2015 .

17. J. Michalski, Methods applicable in computer-aided preliminary design of inland ships (in Polish), Gdansk: Wydawnictwo Politechniki Gdańskiej, 2007.

18. A. Zborowski, Ship resistance (in Polish), Gdansk: Wydawnictwo Uczelniane Politechniki Gdańskiej, 1972.

\section{CONTACT WITH THE AUTHORS}

\author{
Artur Karczewski \\ e-mail:artkarcz@pg.gda.pl \\ Janusz Kozak \\ e-mail:kozak@pg.gda.pl
}

Gdansk University of Technology

Faculty of Ocean Engineering and Ship Technology

Narutowicza 11/12

80-233 Gdansk

Poland 